\title{
Design of the Pneumatic Device of the Some Type of the Laminator
}

\author{
Yan MA ,Yu RONG, Xin YANG, Dong-xu LI, Li-xin CHEN \\ Shenyang Academy of Instrumentation Science, Shenyang City, Liaoning Province, 110043 \\ my9079cn@163.com
}

Keywords: Laminator, Pneumatic Device, Design

Abstract. The pneumatic part of the lamination machine is presented in the paper. The type of cylinder is introduced. The parameters of pneumatic device are designed. The parameter design of the pneumatic device of the box cover, the design of the parameters of the lifting pneumatic device for the cylinder, and the design of the parameters of the clamping pneumatic device is obtained. The pressure needed of the pneumatic device of the box cover, the lifting pneumatic device for the cylinder, the clamping pneumatic device is analyzed. The main parameters of the cylinder are calculated and the volume of the gas is calculated.

\section{Introduction}

Film machine is designed for electronic, communications, semiconductor and other industries posted protective film and anti-riot film machine, to ensure that no bubbles without scratch film. The self-adhesive part of the tape is drawn to the stripping plate under the suction device of the drive device and is self-adhesive under the lead, which is peeled off by a series of tensioning devices and then automatically corrected by the robot Mounted on a work-piece with a fixture. The film machine requires the lifting and lowering of the lid, the opening and clamping of the clip, and the lifting and lowering of the drum. Consider the design of a simple and convenient, easy to operate, and cost issues, the use of pneumatic devices to achieve these actions.

\section{Classification of Cylinder}

The cylinder is a pneumatic actuator that converts the pressure energy of the compressed gas into mechanical energy in the pneumatic transmission. The cylinder has two types of reciprocating linear motion and reciprocating swing. The reciprocating linear motion cylinder can be divided into single acting cylinder, double acting cylinder, diaphragm cylinder and impact cylinder. In the lid and the drum of the lifting and clamping of the clip, the required stroke is relatively short, less air consumption, and the accuracy requirements are not high, the movement is simple. Considering the force and design structure and cost required for the rise and fall of the clamp and the drum, use a single acting cylinder. Cylinder is composed of cylinder, end cap, piston, piston rod and seal. Single-acting cylinder is divided into plunger-type cylinder, piston-type cylinder, film-type cylinder. Support the cylinder cover cylinder, roller movements, the opening and closing of the clip are required to drive the cylinder, so it is related to the choice of the cylinder. According to the different cylinder needs different air intake and different volume[3,4], and the selection for appropriate compressed gas device for assembly is needed.

\section{Design of Parameter of Pneumatic Device}

Cylinder operating characteristics refers to the output of the cylinder, the cylinder pressure changes and the movement of the cylinder speed. 


\section{(1) Parameter Design of Pneumatic Device in Box}

Cover length and width Dimensions: $500 \mathrm{~mm} \times 500 \mathrm{~mm} \times 10 \mathrm{~mm}$. The material used is aluminum. The weight of the lid is $10 \mathrm{~kg}$. The movement speed of the lid is not high, belonging to the low speed movement, the ball screw drive efficiency $\eta=0.5$ The diameter of the primary cylinder is $D=32 \mathrm{~mm}$ and the piston rod is $\mathrm{d}=12 \mathrm{~mm}$

Because $F=\left(A_{1} p_{1}-A_{2} p_{2}\right) \eta$

So $\quad p_{1}=0.24 \mathrm{MPa} \quad ; \quad p_{2}=0.1 \mathrm{MPa}$;

Cylinder low speed movement, $v=20 \mathrm{~mm} / \mathrm{s}$, So $F_{t}=200 \mathrm{~N}$

The diameter of the cylinder $\mathrm{D}$

$D \geq \sqrt{\frac{4 F_{t}}{\pi p}}=\sqrt{\frac{4 \times 200}{\pi \times 0.24}}=32.6 \mathrm{~mm}$

Cylinder Material Casting Aluminum Alloy ZL203, $[\sigma]=30 \mathrm{MPa}$

$$
d \geq \sqrt{\frac{4 F}{\pi[\sigma]}}=\sqrt{\frac{4 \times 100}{\pi \times 30}}=2.06 \mathrm{~mm}
$$

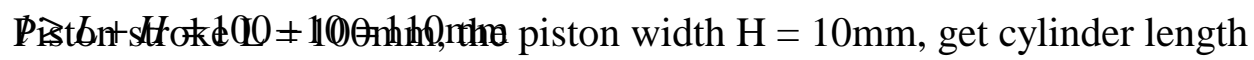

Piston stroke $\mathrm{L}=15 \mathrm{~mm}$, piston width $\mathrm{H}=5 \mathrm{~mm}$, cylinder length

Cylinder wall thickness $\delta=\frac{p D}{2[\sigma]+C}=\frac{0.24 \times 32}{2 \times 30}=0.182 \mathrm{~mm} \quad$ Take $\delta=2 \mathrm{~mm}$

The theoretical air consumption of the cylinder: $V=\frac{4}{\pi} D^{2} L=\frac{4}{\pi} \times 32^{2} \times 100=80425 \mathrm{~mm}^{3}$

Actual air consumption : $V_{s}=1.5 \mathrm{~V}=120638 \mathrm{~mm}^{3}$

Pressurized air consumption: $q_{s}=\frac{V_{S}}{t}=24128 \mathrm{~mm}^{3} / \mathrm{s}$ (The action time is 5 seconds)

Actual free air consumption: $V_{s z}=V_{s} \frac{p+0.1013}{0.1013}=406454 \mathrm{~mm}^{3}$

Actual free air consumption flow: $q_{s z}=q_{s} \frac{p+0.1013}{0.1013}=81292 \mathrm{~mm}^{3} / \mathrm{s}$

Cylinders are scaled twice every minute, then the use of micro-displacement of $3 \mathrm{~L} / \mathrm{min}$ pneumatic device. The lid is selected for gravity automatic reset.

\section{(2) Parameter Design of Roller Lifting Pneumatic Actuator}

Drum diameter of $50 \mathrm{~mm}$, length $400 \mathrm{~mm}$, the material can be used plastic. The drum weighs about $2 \mathrm{~kg}$, plus other parts, the pneumatic device needs to raise the weight of $5 \mathrm{~kg}$.

The diameter of the primary cylinder is $\mathrm{D}=20 \mathrm{~mm}$ and the piston rod is $\mathrm{d}=8 \mathrm{~mm}$ $F=\left(A_{1} p_{1}-A_{2} p_{2}\right) \eta$

So $p_{1}=0.33 \mathrm{MPa} ; p_{2}=0.1 \mathrm{MPa} ; \quad F_{t}=100 \mathrm{~N}$

The diameter of the cylinder $\mathrm{D}$

$D \geq \sqrt{\frac{4 F_{t}}{\pi p}}=\sqrt{\frac{4 \times 100}{\pi \times 0.33}}=20.6 \mathrm{~mm}$

The diameter of the circle $D=20 \mathrm{~mm}$, and $d=8 \mathrm{~mm}$ 
Cylinder Material Casting Aluminum Alloy ZL203, $[\sigma]=30 \mathrm{MPa}$

So

$d \geq \sqrt{\frac{4 F}{\pi[\sigma]}}=\sqrt{\frac{4 \times 50}{\pi \times 30}}=1.46 \mathrm{~mm}$

meets this

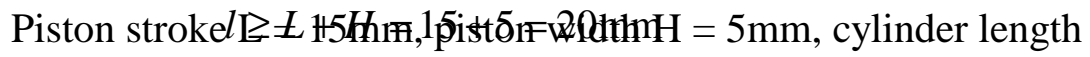

Cylinder wall thickness

$\delta=\frac{p D}{2[\sigma]+C}=\frac{0.33 \times 20}{2 \times 30}=0.11 \mathrm{~mm} \quad($ Margin $\mathrm{C}$ is zero ) Take $\delta=2 \mathrm{~mm}$

The theoreticat air consumption of the cylinder
$V=\frac{-D^{2} L}{2}=-\times 20^{2} \times 10=5093 \mathrm{~mm}^{3}$

$\pi \quad \pi$

Actual air consumption $V_{s}=1.5 \mathrm{~V}=7640 \mathrm{~mm}^{3}$

Pressurized air consumption $q_{s}=\frac{V_{S}}{t}=7640 \mathrm{~mm}^{3} / \mathrm{s} \quad$ (The action time is 5 seconds )

Actual free air consumption $\quad V_{s z}=V_{s} \frac{p+0.1013}{0.1013}=32528 \mathrm{~mm}^{3}$

Actual freet dirlodisumption flow

$q_{s z}=q_{s} \frac{0.1013}{0}=32528 \mathrm{~mm}^{3} / \mathrm{s}$

\section{(3) Parameter Design of Clamp Pneumatic Device}

The initial tension required to pull the film is about $10 \mathrm{~N}$, plus a series of resistance in the middle drive, the friction coefficient between the fixture and the film is 0.8 , then the force applied by the fixture is $20 \mathrm{~N}$. Because the need for both sides of the clamping, so the side of the required force is $10 \mathrm{~N}$.

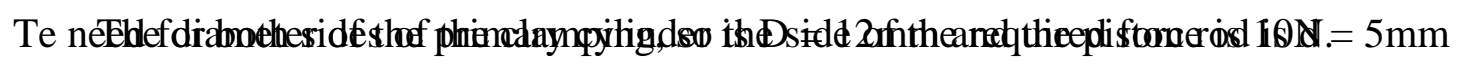

Piston rod movement speed is $v=50 \mathrm{~mm} / \mathrm{s}$, Belonging to low-speed movement, transmission efficiency is $\eta=0.5$

So $\quad p_{1}=0.19 \mathrm{MPa} \quad p_{2}=0.1 \mathrm{MPa}, \quad F_{t}=100 \mathrm{~N}$

The diameter of the cylinder D $D \geq \sqrt{\frac{4 F_{t}}{\pi p}}=\sqrt{\frac{4 \times 20}{\pi \times 0.19}}=11.6 \mathrm{~mm}$

The diameter of the circle is $D=12 \mathrm{~mm}$, So $d=5 \mathrm{~mm}$

Cylinder Material Casting Aluminum Alloy ZL203, $[\sigma]=30 \mathrm{MPa}$

$d \geq \sqrt{\frac{4 F}{\pi[\sigma]}}=\sqrt{\frac{4 \times 10}{\pi \times 30}}=0.65 \mathrm{~mm}$

Pætbntsifoke $\mathbf{L}+5$ 500mmiston width $\mathrm{H}=5 \mathrm{~mm}$, cylinder length

Cylinder wall thickness 
$\delta=\frac{p D}{2[\sigma]+C}=\frac{0.19 \times 12}{2 \times 30}=0.04 \mathrm{~mm} \quad$ Take $\delta=2 \mathrm{~mm}$

The theoretical air consumption of the cylinder

Actual air consumption $\quad V_{s}=1.5 \mathrm{~V}=2751 \mathrm{~mm}^{3}$

Pressurized air consumption $q_{s}=\frac{V_{S}}{t}=2751 \mathrm{~mm}^{3} / \mathrm{s}$

Actual free air consumption $V_{s z}=V_{s} \frac{p+0.1013}{0.1013}=7911 \mathrm{~mm}^{3}$

Actual fręequingansumption flow

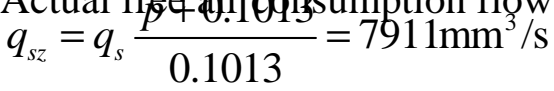

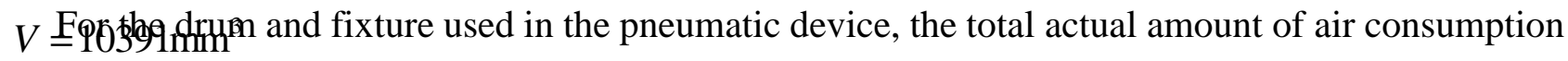

Roller and clamp pneumatic devices are reset with spring force.

\section{Conclusions}

The part of the pneumatic device of the film machine is analyzed. The diameter of the cylinder, the thickness of the cylinder wall, and a series of parameters is determined, and the required gas volume is calculated. In the field of machinery, continuous optimization of product structure and data is gained by engineers . Experience of predecessors is worth our reference and respect, continuous innovation is needed, and more good product is waiting to be created.

\section{Acknowledgements}

Thanks for the support of Shenyang Academy of Instrumentation Science. Thanks for the help from Peng HUANG.

\section{References}

[1] Gong Yun Peng, Tian Wan Lu ,Zhang Wei Hua ,Huang Qiu Bo. Design of Mechanical Design Course. Beijing: Science Press, (2008)

[2] Sun Zhi Li,Ma Xing Guo,Huang Qiu Bo, Yan Yu Tao. Mechanical Design. Beijing: Science Press, (2008)

[3] Xie Qun, Cui Guang Chen, Wang Jian. Hydraulic and Pneumatic Transmission. Beijing: National Defense Industry Press, (2015)

[4] Tian Dangfang. Study and Design of Small Twin-screw Air Compressor Structure. Wuhan University of Technology, (2014)

[5] Peng HUANG. Design of Some Type of Mounter. Northeastern University,(2016)

[6] Tang Meng. State and Simulation Analysis of Translating Piston Air Compressor.Guangxi University, (2011) 